Abstracta Iranica Abstracta Iranica

Revue bibliographique pour le domaine irano-aryen

Volume 26 | 2005

Comptes rendus des publications de 2003

\title{
Gušeh-ha'i az tārikh-e frāmāsoneri-ye Iran / Aspects of the history of Freemasonry in Iran. Bethesda, Ibex publishers, 2002.
}

Mahmoud Delfani

\section{(2) OpenEdition}

1 Journals

\section{Édition électronique}

URL : http://journals.openedition.org/abstractairanica/2903

DOI : 10.4000/abstractairanica.2903

ISSN : 1961-960X

Éditeur :

CNRS (UMR 7528 Mondes iraniens et indiens), Éditions de l'IFRI

\section{Édition imprimée}

Date de publication : 15 mai 2005

ISSN : 0240-8910

Référence électronique

Mahmoud Delfani, " Gušeh-ha'i az tārikh-e frāmāsoneri-ye Iran / Aspects of the history of Freemasonry in Iran. Bethesda, Ibex publishers, 2002. », Abstracta Iranica [En ligne], Volume 26 | 2005, document 267 , mis en ligne le 08 décembre 2005, consulté le 25 septembre 2020. URL : http://

journals.openedition.org/abstractairanica/2903; DOI : https://doi.org/10.4000/abstractairanica.2903

Ce document a été généré automatiquement le 25 septembre 2020.

Tous droits réservés 


\title{
Gušeh-ha’i az tārikh-e frāmāsoneri-ye Iran / Aspects of the history of Freemasonry in Iran. Bethesda, Ibex publishers, 2002.
}

\author{
Mahmoud Delfani
}

1 Le regard que la politique a posé sur la franc-maçonnerie avant et après la Révolution Islamique dresse plusieurs obstacles face aux études historiques sur ce sujet. Cela explique que malgré l'importance du sujet et l'abondance des sources reposant en archives, nous ne possédons pas grand chose sur les franc-maçonneries iraniennes. Mis à part certains livres comme celui de Esmā̄î̀ Rā'īn (FarāmūššHāne va farāmāsonerī dar İrān), il y a bien peu de choses sur le sujet. Certains franc-maçons comme (Alī-Akbar DehHुodā, Kamāl ol-Molk, ŠeyH Ebrāhīm Zanjānī, ont pourtant joué un rôle important dans l'histoire contemporaine d'Iran. Le présent ouvrage tire son importance du fait que pour la première fois un franc-maçon iranien écrit ses mémoires et révèle certains documents sur ce sujet.

2 L'A. s'efforce d'écrire l'histoire de la franc-maçonnerie dans le cadre d'une autobiographie où la plupart des documents publiés sont ses lettres personnelles. Il propose donc une vue de l'intérieur du phénomène. Bien que l'ouvrage ne soit pas une étude historique, l'A. se concentre sur l'histoire de cette organisation à l'époque de Moḥammad-Reḍā Šāh Pahlavī. En critiquant les ouvrages publiés sur la francmaçonnerie, comme ceux de E. Rā'īn, de A. Nejātī et de H. Mīr, l'A. essaie de corriger les éléments qui selon lui, ont été falsifiés. A travers une douzaine de chapitres, il essaie de défendre ses quarante ans d'activités: Rouhani, avec Mahmoud Human, a été le fondateur de la grande loge en Iran et pendant neuf ans a occupé la plus haute place dans la franc-maçonnerie iranienne. En s'appuyant sur la question de la légitimité des loges iraniennes, l'A. explique l'histoire de chaque loge, autorisée par les grandes loges françaises ou anglaises. D'après lui, les loges inspirées et autorisées par le Grand Orient de France ne sont pas valables. Les relations des loges iraniennes avec celles d'Europe, 
les détails sur la fondation des loges en Iran, le shah et ses rapports avec la francmaçonnerie et la situation des francs-maçons constituent les passages importants de ce livre. Cependant, ce qui est frappant, c'est le destin de la franc-maçonnerie en exil et après la révolution islamique. Puisque la franc-maçonnerie était considérée comme une activité criminelle et illégale, les francs-maçons ont essayé de réorganiser leurs loges en exil. Un des passages intéressants de ce livre est le récit de la rivalité entre les loges iraniennes pour obtenir l'autorisation des grandes loges américaines. Les rapports sur les réunions des francs-maçon, leurs cérémonies, la fondation de la première loge iranienne à l'étranger en 1988 et ses activités, sont particulièrement intéressants. Dans les chapitres dix, onze et douze, l'A. tente de justifier son opposition au grand maitre de la loge iranienne, Bāqer Hey'at. En révélant certains documents et lettres personnels, il essaie de mettre en cause la légitimité du grand maître. A ce titre, il accuse même B. Hey'at de complicité avec l'autorité iranienne lors de son arrestation en Iran. Les trois derniers chapitres contiennent également des informations inédites sur la francmaçonnerie iranienne aux États-Unis. En définitive, outre une mine d'informations historiques, ce livre se veut un hommage aux francs-maçons, en reprenant la vieille argumentation qui consiste à mettre en valeur le rôle des francs-maçons iraniens dans la modernisation du pays.

INDEX

Thèmes : 4.3. Histoire de l'Iran moderne (à partir de 1905)

\section{AUTEURS}

\section{MAHMOUD DELFANI}

Paris 